\title{
Pollution Abatement Investment When Firms Lobby Against Environmental Regulation
}

\author{
Y. Hossein Farzin ${ }^{1} \quad$ Jinhua Zhao
}

February 2, 2004

${ }^{1}$ Corresponding author. Farzin is professor, Department of Agricultural and Resource Economics, University of California, Davis, CA 95616. Voice: 530-752-7610. Fax: 530752-5614. Email: farzin@primal.ucdavis.edu. Zhao is associate professor, Department of Economics, Iowa State University, Ames, IA 50011. Voice: 515-294-5857. Fax: 515-294-0221. Email: zhao@iastate.edu.

For helpful comments on the earlier versions of the paper, we thank participants at the Third International Conference on Public Economics, Paris, July 4-6, 2002, and the AAEA annual meetings, Chicago, August 5-8, 2001. 


\begin{abstract}
We study a firm's optimal lobby behavior and its effect on investment in pollution abatement capital. We develop a dynamic framework where a representative firm can invest in both abatement and lobby capital in response to a possible future increase in pollution tax. We show that when the firm lobbys against the scale of the tax increase at a predetermined date, it will act like an occasional lobbyer by investing a lump-sum (optimal) amount in the lobby capital only at that date. But, to delay the new tax, it will act like a habitual lobbyer by investing continously and at increasing rates over an optimal time period. We show that lobby expenditure crowds out investment in abatement capital and that this effect is stronger the more efficient is the lobbying activity. Further, we show that while uncertainty about the magnitude of the tax reduces the firm's incentive to lobby, uncertainty about the timing of the new tax increases it.
\end{abstract}




\section{Introduction}

One of the main merits attributed to the market-based environmental regulations such as pollution tax or tradable permits is that they give firms incentive to invest in environmentally cleaner technologies. However, as is well understood from the classic works of Olson (1965), Stigler (1971), Peltzman (1976), Tullock (1980, 1989), and Becker $(1983,1985)$, and the more recent contributions by Bernheim and Winston (1986b), Grossman and Helpman (1994), Dixit, Grossman and Helpman (1997), and Persson (1998), among others, in general, the regulatory outcomes depend on lobby powers of the private interest groups. Thus, in reality, active lobbying by polluting firms counteracts both the design and effectiveness of environmental regulations. For instance, while the possibility of a future increase in pollution tax encourages firms to invest in pollution abatement equipment, it also gives them incentive to spend resources on lobby efforts to mitigate the future tax increase. The lobby effort can either reduce the stringency of the regulation to be mandated (for example, a lower emissions standard, a smaller pollution tax increase, a larger amount of initial pollution permits, or a free distribution of emission permits to existing firms), or delay the date at which the regulation becomes effective, or both ${ }^{1}$. In either case, investment in lobbying against environmental regulation may "crowd out" abatement investment: firms may find it profitable to divert some of their resources from investment in pollu-

\footnotetext{
${ }^{1}$ Thus, for example, attempting to delay Clean Air Regulations, "the auto industry wasted no time in rallying a vast network of dealers and supplier to bring its message to Capitol Hill. Chrysler officials not only went to their suppliers, they also used their employees. An internal Chrysler memorandum dated March 23m 1977 for J.C. Moore, the company's manager for public relations, asked all plant managers and their staff to give the company the legal right to send mailgrams to Congress under their names to support legislation to delay and weaken auto emission standards" (Doyle (2000, p. 134 )).
} 
tion abatement technologies to expenditures on lobby efforts ${ }^{2}$. This possibility raises a number of important questions. For example, what are the characteristics of the firm's optimal lobby behavior? How would lobby expenditure affect the timing or the stringency of environmental policy? How does lobby affect the firm's path of investment in abatement capital? How does uncertainty about the size of a future tax increase or the timing of its enactment affect the firm's lobbying effort?

An insightful literature has emerged in recent years on the political economy of environmental policy making. This literature, in the framework of common agency (Bernheim and Whiston, 1986a), typically concentrates on competition between two opposing lobby groups (industrialists and environmentalists) through campaign contributions and examines the effect of this competition on environmental policy outcome. For example, Bartsch, Rauscher and Thomas (1993) consider two distinct settings: one in which the contributions by each lobby promotes the chance of its favored political candidate being elected, while the environmental policy agenda of the candidates are taken to be exogenously set, and the other where the lobbying activities influence the existing government's environmental policy. They show the possibility that the interaction between the two interest groups may harm (benefit) them by raising (reducing) their lobby efforts. Following Grossman and Helpman (1994)'s menu auction model, Fredrikson (1997) considers the case of a small open economy where the government's probability of electoral success depends both on aggregate campaign contributions and on aggregate social welfare. He shows that the

\footnotetext{
${ }^{2}$ A good example is lobbying by US automakers against CAFÉ (Corporate Average Fuel Economy) standards, established after the 1973 energy crisis by U.S. goverment, requiring U.S. aoutomakers to meet increasingly stringent milage standards (from an average of 13.2 MPG in 1974 to 27.5 MPG by 1985). However, as is well documented in Doyle (2000), after 1982, under pressure from automakers' lobby, the CAFE standards were repeatedly rolled back. In early October, Department of Transportation (DOT) had rolled back the 1989 CAFE standards to 26.5 MPG, from the original standard of 27.5 MPG set to be achieved by 1985 .
} 
political equilibrium tax rate differs from the Pigouvian rate and depends on lobby group membership, the government's weight on aggregate social welfare relative to campaign contribution and the tax elasticity of pollution. Fredriksson and Gaston (2000) examine the effect of lobby and competition for capital on environmental governance in a federal system. They argue that the move to centralized regulation stimulates industry lobby against environmental regulation, thus explaining why industry lobby may be stronger at the federal level than at lower administration levels. Gulati (1999) develops a general equilibrium model much in the spirit of the models developed by Dixit, Grossman, and Helpman (1997) and Fredrikson (1997) to compare the optimal pollution tax under a conventional social planner and a common agency government. In her model, both capital owners and workers lobby to influence the tax rate. She finds that while distributional consideration may compel the social planner to use pollution tax to correct income inequality, the common agency government uses the optimal pollution tax to completely internalize the environmental externality without correcting the inequality.

In contrast to the foregoing studies, which consider competition between industry and environmental lobby groups, several papers focus on industry lobby only and examine its effects on environmental policy. Thus, for example, Schleich and Orden (2000) adopt Grossman and Helpman's (1994) model to analyze the effect of organized industry lobby on the domestic and trade policies when the home and foreign country governments may act cooperatively or non-cooperatively. They show that while governments choose the most efficient policies from the set of available policies, lobbies may prefer less efficient policies. Further, the inefficient trade policies, which the industry lobby prefers, can result in higher environmental quality. Michaelis (1994) departs from the conventional assumption in the theoretical literature that the industry lobby acts as a single coalition with the same interest. He examines 
a heterogeneous Cournot-Nash oligopoly with endogenous policy making where two groups of firms (differentiated by their compliance costs) engage in strategic lobbying by making campaign contributions to two rival political parties competing for contributions. Damania (2001) adopts the common agency framework to study the situation where firms can commit to certain abatement technologies. Adopting, or committing to less efficient abatement technologies acts as a credible signal to the government that profits and hence welfare and political contributions will decrease if a high pollution tax rate is introduced.

Our paper differs from the literature reviewed above in several significant respects. First, we abstract from the process by which lobby activity influences the outcome of the regulator's decision about the future tax rate. Rather, we consider a general reduced-form relationship between the stock of lobby expenditure and the likely resulting (political equilibrium) tax rate or the date of its implementation. ${ }^{3}$ Second, by assuming that the lobby activity of the representative competitive firm is coordinated by the industry lobby, we abstract from possibilities of free riding by firms in their lobby efforts. ${ }^{4}$ Third, in contrast to the existing literature that analyzes the effects of lobby activity in a static framework, we develop a dynamic optimization model to analyze the optimal decisions of a typical firm about investments both in lobby activities and in abatement capital. The dynamic approach enables us to highlight the time path of the lobby activity. Fourth, we compare the effects of lobbying when the environmental regulation is uncertain with those under certainty.

In response to the tax increase, the firm may invest in the stock of pollution abate-

\footnotetext{
${ }^{3}$ By doing so, in effect, we extend Farzin and Kort's (2000) model to the more realistic situation where the future tax rate and the date of its enactment are endogenized by the firm's decision to invest in lobby capital.

${ }^{4}$ To avoid the familiar free-riding problem, we assume that the lobby efforts of firms are well coordinated through a single lobby agency that acts on behalf of the polluting industry. This assumption enables us to investigate a "representative" firm's decision.
} 
ment equipment to lower the pollution intensity of its output, or in "lobby capital" to influence the future emission tax policy. The pay off from "lobby investment" may take the form of a smaller future tax increase, or a delay in the enactment date of the tax increase, or both. To reflect one of the political economy features of environmental policy legislation, we allow the policy mitigating impact of a given stock of lobby capital to decline with time, i.e., past lobby expenditures are less effective than current ones in affecting current policy making. This novel approach captures the dynamic process of lobby activities, and includes as a special case the conventional static approach that allows current policy to be affected by current lobby contributions only. The dynamics of the abatement and lobby investments are specified in the model setup in section 2 .

We begin in section 3 with a simple situation where the effective date of the tax increase is known with certainty and not subject to the firm's lobby activity. The magnitude of the future tax increase, however, is assumed uncertain, giving the firm an opportunity to invest in lobby efforts to reduce the (expected) size of the increase. We show that while the firm's optimal abatement investment policy is to gradually build up abatement capital stock towards a steady-state level, its optimal lobby policy requires no lobby activity prior to the date of the tax increase but a once-and-for-all (optimal) lump-sum lobby effort immediately before that date. Interestingly, we find that uncertainty about the magnitude of the future tax reduces the firm's incentive to lobby, thus mitigating the adverse effect of uncertainty on investment in abatement capital.

In section 4, we consider the case where the size of the future tax increase is known with certainty and not amenable to the firm's lobby activity, but the date of implementation can be delayed by lobbying. Again, the firm gradually builds up its abatement capital stock towards a steady state level. However, the optimal 
lobby policy in this case requires a gradually increasing level of lobby capital stock right from the beginning until the policy changes. Further, in contrast to the case of uncertainty about the size of the future tax, uncertainty about the timing of the

tax policy increases the firm's incentive to invest in lobbying, thereby aggravating the adverse effect of uncertainty on abatement investment. Concluding remarks are given in section 5 .

\section{Model Setup}

Consider a price taking firm whose output causes pollution damage that can be reduced by abatement capital. Let $q_{t}$ be its output at time $t$, and $g\left(q_{t}\right)$ be the cost of production, with $g^{\prime}>0$ and $g^{\prime \prime}>0$. The emission from production is $\alpha\left(K_{t}\right) q_{t}$ where $K_{t}$ is the abatement capital stock, with $\alpha^{\prime}<0$ and $\alpha^{\prime \prime}>0$. Thus, for the same output, higher abatement capital stock reduces the emission level at a decreasing rate. Let $I_{t}$ be the firms' rate of investment in abatement capital, and the cost be $c\left(I_{t}\right)$, with $c^{\prime}>0$ and $c^{\prime \prime}>0$. Abatement capital depreciates at the rate of $\delta$, so the equation of motion for $K_{t}$ is given by

$$
\dot{K}_{t}=I_{t}-\delta K_{t}
$$

Currently the firm pays a pollution tax $\tau_{l}$ for its emission. This tax rate may increase in the future, and the firm can lobby to reduce the magnitude of the increase, or to delay its implementation. The effectiveness of its lobbying at time $t$ depends on the stock of its "lobby capital" $B_{t}$. The lobby capital being a stock variable reflects the variety of lobby processes: the firm can influence policy makers either through continuous contacts or by discrete contributions. By considering the stock of lobby capital, we recognize the fact that often a prolonged and sustained lobbying effort is required before the firm can establish an effective relationship with policy makers 
and influence their decisions. However, earlier contributions may not be as effective as current contributions. We capture this possibility by allowing the lobby capital to depreciate, at rate $\gamma$. The depreciation rate may reflect the instability overtime of the firm's relationship with regulators and politicians. If the latter can possibly change or lose their jobs, so that the firm may have little use of past lobbying when new politicians take office, $\gamma$ may equal the hazard rate, or the conditional probability of such events. Let $l_{t}$ be the lobby expenditure rate at time $t$. The equation of motion for $B_{t}$ is

$$
\dot{B}_{t}=l_{t}-\gamma B_{t}
$$

Without loss of generality, we assume that $B_{0}=0$ and $K_{0}$ is low.

We consider two mechanisms by which $B_{t}$ affects the tax policy. First, lobbying can reduce the possible magnitude of the tax increase. For example, if the regulation governing the tax level, say the Clean Water Act, is scheduled to be renewed or modified at a future date, the polluting firms may lobby to reduce the possible future tax increase. Second, lobbying can delay a predetermined tax increase. For example, the auto industry has been rather successful in delaying the government regulation on low-emission cars.

\section{Lobby Against the Magnitude of Tax Increases}

In this section, we study the optimal lobby effort when lobby can reduce the magnitude of the tax increase. We first study an uncertain tax increase, where we let the possible future tax rate be a uniformly distributed random variable, and lobby reduces the upper bound. We then compare the effect with the case of an equivalent deterministic tax increase to study the effects of uncertainty. 


\subsection{Optimal Lobby Under Uncertainty}

Suppose the time of the tax increase is fixed at $T>0$, but the level of the tax change is undecided. Without loss of generality, let the possible future tax rate $\tau$ be uniformly distributed on $\left[\tau_{l}, \tau_{h}\left(B_{T}\right)\right]$, with $\tau_{h}^{\prime}<0$ and $\tau_{h}^{\prime \prime}>0$. Thus, lobbying can reduce, at decreasing returns to scale, the upper bound of the (uncertain) tax increase, and it is the lobby capital at the moment of the tax change that matters. Note that lobby reduces both the expected tax rate and the uncertainty in the new rate. Lobbyists, by maintaining close ties with regulators, often bring information to firms about the likely regulation, reducing the firms' uncertainties. ${ }^{5}$

After time $T$, the firm has no incentive to lobby since the new policy has already been determined. That is, $l_{t}=0$ for $t>T$. Because lobby capital $B$ depreciates, and it is the stock at moment $T$ that affects the new policy, the firm has no incentive to spend on lobbying before $T$ either. That is, $l_{t}=0$ for $t<T$. The optimal strategy is to invest in the lobby capital at the moment of the policy change. The capital stock $B_{T}$ jumps from zero to the optimal level $B_{T}^{*}: B_{T^{+}}-B_{T^{-}}=B_{T^{*}}^{*}$. The firm is thus an "occasional lobbyer" (Morck, et al. 2001), engaging in lobby activities only when the policy change is imminent. ${ }^{6}$

\footnotetext{
${ }^{5}$ As noted earlier, the function $\tau_{h}\left(B_{T}\right)$ can be thought to encapsulate in a general reduced form the equilibrium outcome of a game between the firm and a regulator where the regulator offers policy favors in the form of mandating a lower tax increase (or deferring the date of tax reform enactment) in return for lobby funds from the firm. Alternatively, noting that, besides direct political contributions, lobby resources are spent on a wide variety of other activities that put pressure on plociy makers to mitigate the stringency of regulations, the function $\tau_{h}\left(B_{T}\right)$ can also be interpreted to reflect the outcome of such lobbying expenditures. Ideally one would have liked to explicitly model the game between the regulator and the firm and explicitly derive the equilibrium outcomes (as in, for example, Michaelis (1994), Fredrikson (1997), Fredriksson and Gaston (2000), and Damania (2001), among others). However, that would significantly complicate the analysis in a dynamic model.

${ }^{6}$ Evidences abound where firms lobby intensively in the face of pending regulation. For example, In
} 
For $t \geq T$ and given the lobby stock $B_{T}$, the firm observes the new tax rate $\tau \in\left[\tau_{l}, \tau_{h}\left(B_{T}\right)\right]$. Then its optimal decision on abatement investment $I_{t}$ is given by

$$
J\left(K_{T}, \tau\right) \equiv \max _{q, I} \int_{T}^{\infty} e^{-r(t-T)}[p(t) q(t)-g(q(t))-\tau \alpha(K(t)) q(t)-C(I(t))] d t
$$

subject to (1), with $K(T)=K_{T}$, and the exogenously given price process $\{p(t), t \geq$ $T\}$.

At any $t$, given $p_{t}, K_{t}$, and $\tau$, the optimal output level $q_{t}^{*}$ is given by the static first order condition $p_{t}-\tau \alpha\left(K_{t}\right)=g^{\prime}\left(q_{t}\right)$. Since $\alpha^{\prime}<0$ and $g(\cdot)$ is convex, we know $q_{t}^{*}$ is increasing in $K_{t}$. Substituting $q^{*}$ into (3), we obtain the per period profit as

$$
\pi(\tau, K)=p q^{*}(p, \tau, K)-g\left(q^{*}\right)-\tau \alpha(K) q^{*}
$$

Then (3) becomes a standard optimal control problem with one state $\left(K_{t}\right)$ and one control $\left(I_{t}\right)$ variables. There is a unique steady state to the optimal solutions, $\left(I^{*}, K^{*}\right)$, which is a saddle point. Along the (unique) optimal path, both $I_{t}^{*}$ and $K_{t}^{*}$ are monotone in $t$. As a result, we can show through the phase diagram that if the initial abatement capital $K_{T}$ is higher, the optimal capital $K_{t}^{*}$ is higher and the optimal investment rate $I_{t}^{*}$ is lower, along the entire path before reaching the steady state (see Appendix A). That is, $K_{t}^{*}$ is increasing and $I_{t}^{*}$ is decreasing in $K_{T}$ for all $T<t<\infty$.

late January 1991, when the 102nd U.S.Congress convened, Senator Bryon (Democrat from Nevada) introduced his new CAFE standard bill, proposing a 20 percent increase in fuel economy by 1995 and a 40 percent improvement by the year 2001. It was expected that achieving the CAFE standards in his bill, would reduce America's energy consumption by 2.5 million barrels per day by the year 2005 and also reduce carbon dioxide emissions by 440 tons annually. "By the early spring 1991, the Big Three automakers (GM, Ford, and Chrysler) had begun to unleash a multimillion dollar lobbying and organizing campaign build around the Coalition for Vehicle Choice (CVC). Before long, the CVC would spend $\$ 8$ million on the anti-Byron CAFE effort, launch a nationwide media blitz, and enlist more than 200 groups into the CVC" (Dole (2000, p.259)). 
Note that the steady state is independent of $K_{T}$ : it is unique, determined entirely by the abatement technology, cost of abatement investment, and the new tax rate $\tau$.

Using the envelope theorem, we know from (3) that

$$
\frac{\partial J\left(K_{T}, \tau\right)}{\partial \tau}=-\int_{T}^{\infty} e^{-r(t-T)} \alpha\left(K_{t}^{*}\right) q_{t}^{*} d t
$$

which in turn implies

$$
\frac{\partial^{2} J\left(K_{T}, \tau\right)}{\partial \tau \partial K_{T}}=-\int_{T}^{\infty} e^{-r(t-T)} \frac{\partial\left(\alpha\left(K_{t}^{*}\right) q_{t}^{*}\right)}{\partial K_{t}} \frac{\partial K_{t}^{*}\left(K_{T}, \tau\right)}{\partial K_{T}} d t
$$

As the capital stock $K_{t}^{*}$ increases, the pollution intensity $\alpha\left(K_{t}^{*}\right)$ decreases, but the output $q_{t}^{*}$ increases. For our problem to be interesting, we make the following intuitive assumption:

Assumption 1 Given price $p$ and tax $\tau$, the total pollution, $\alpha(K) q^{*}(p, \tau, K)$, decreases in the stock of abatement capital $K$.

This is the case if the output response to a higher $K$ is smaller than the response of the pollution intensity. ${ }^{7}$ Then, since $K_{t}^{*}$ increases in $K_{T}$, we know $J_{K_{T} \tau}>0$ : the marginal value of the capital stock $K_{T}$ increases in the future tax rate.

Let $V\left(K_{T}, B_{T}\right)=E_{\tau \mid \tau_{h}\left(B_{T}\right)} J\left(K_{T}, \tau\right)$ be the firm's expected future payoff after period $T$. Since $\tau_{h}\left(B_{T}\right)$ is decreasing in $B_{T}$, as the lobby capital $B_{T}$ rises, the distribution of $\operatorname{tax} \tau$ decreases in the sense of first order stochastic dominance. Because $J_{K_{T}}$ is monotone increasing in $\tau$ (noting that $J_{K_{T} \tau}>0$ ), we know the marginal expected value of the abatement capital stock at $T, V_{K_{T}}=E_{\tau \mid \tau_{h}\left(B_{T}\right)} J_{K_{T}}$, decreases as $B_{T}$ rises. That is, being able to lobby down the future tax rate reduces the marginal value of the "starting" capital stock after the tax change.

\footnotetext{
${ }^{7}$ In particular, $\frac{d}{d K}(\alpha q)=\frac{\alpha q}{K}\left(\epsilon_{K}^{\alpha}+\epsilon_{K}^{q}\right)$, where $\epsilon_{K}^{\alpha}=\alpha^{\prime}(K) \frac{K}{\alpha}$ and $\epsilon_{K}^{q}=q^{\prime}(K) \frac{K}{q}$ are the elasticities of $\alpha$ and $q$ in $K$. Thus total pollution $\alpha q$ decreases in $K$ if $\left|\epsilon_{K}^{\alpha}\right|>\left|\epsilon_{K}^{q}\right|$.
} 
The firm's optimal decision problem for $t \leq T$ is

$$
\begin{aligned}
\max _{q, I, B_{T}} & \int_{0}^{T} e^{-r t}\left[p(t) q(t)-g(q(t))-\tau_{l} \alpha(K(t)) q(t)-C(I(t))\right] d t \\
& +e^{-r T}\left[V\left(K(T), B_{T}\right)-B_{T}\right]
\end{aligned}
$$

subject to (1), with $K(0)=K_{0}, B_{0}=0, K(T)$ free, and the exogenously given price process $\{p(t), t \leq T\}$. Thus the optimal lobby expenditure is given by $V_{B}\left(K_{T}, B_{T}^{*}\right)=$ 1 , or

$$
\frac{\partial E_{\tau \mid \tau_{h}\left(B_{T}\right)} J\left(K_{T}, \tau\right)}{\partial B_{T}}=\frac{\partial}{\partial B_{T}}\left[\int_{\tau_{l}}^{\tau_{h}\left(B_{T}\right)} \frac{J\left(K_{T}, \tau\right)}{\tau_{h}\left(B_{T}\right)-\tau_{l}} d \tau\right]=1
$$

Further, from the first order conditions, we can show that, since $V_{K_{T} B_{T}}<0$, being able to lobby reduces the abatement investment $I_{t}$ for all $t<T$.

Therefore, the discrete lobby expenditure reduces the abatement investment continuously before the policy change, and results in a smaller ending abatement capital stock. After the tax change, depending on the new tax rate $\tau$, the investment rate $I_{t}$ may jump initially. It is smooth again afterwards. Before the tax change, the lobby expenditure "crowds out" abatement expenditure by reducing the latter's marginal value. After the tax change, the expected abatement investment is reduced because the tax rate is expected to be smaller.

\subsection{The Effects of Uncertainty}

To show the effects of uncertainty, we consider the optimal lobby behavior under certainty where the future tax rate is given by

$$
\hat{\tau}\left(B_{T}\right)=E_{\tau \mid \tau_{h}\left(B_{T}\right)} \tau=\frac{\tau_{l}+\tau_{h}\left(B_{T}\right)}{2} .
$$

Thus, $\hat{\tau}\left(B_{T}\right)$ is the expected tax rate, and its reduction in response to lobby capital $B_{T}$ equals the expected reduction in the uncertainty case.

Similar to the case of certainty, we can show that the optimal lobby behavior is to immediately raise the lobby capital at moment $T$ to its optimal level, denoted by 
$\hat{B}_{T}$ and given by

$$
\frac{\partial J\left(K_{T}, \hat{\tau}\left(B_{T}\right)\right)}{\partial B_{T}}=1 .
$$

Comparing (7) and (9), we know that the firm has less incentive to lobby under uncertainty if and only if

$$
\frac{\partial E_{\tau \mid \tau_{h}\left(B_{T}\right)} J\left(K_{T}, \tau\right)}{\partial B_{T}}<\frac{\partial J\left(K_{T}, \hat{\tau}\left(B_{T}\right)\right)}{\partial B_{T}} .
$$

We show in Appendix B that

Proposition 1 Suppose either (i) the uncertainty level is low (i.e., $\tau_{h}-\tau_{l}$ is small) or (ii) $J_{\tau \tau \tau \tau}\left(K_{T}, \tau\right)=0$. Then a sufficient condition for (10) is $J_{\tau \tau \tau}\left(K_{T}, \tau_{l}\right) \geq 0$.

Thus, if the problem in (6) is linear quadratic (i.e., if the firm's instantaneous payoff function is quadratic), the sufficient conditions in the Proposition 1 are satisfied. The major underlying intuition for (10) is that the benefit function $J\left(B_{T}, \tau\right)$ is convex in $\tau$ (Appendix B). ${ }^{8}$ Thus, all else equal, the firm would prefer a more uncertain tax to a less uncertain tax, and, a fortiori, to a certain tax at the corresponding expected tax rate. In fact, the smaller the uncertainty about the tax rate the lower the premium in payoff from facing an uncertain tax over the payoff from facing the corresponding certain tax rate. Now, in the certainty case, the lobby capital lowers the future tax rate only, which is a beneficial effect. On the other hand, in the case of uncertainty, the lobby capital, by reducing $\tau_{h}$, reduces the expected tax as well as the uncertainty of the tax. Given the convexity of $J(\cdot)$, the latter effect is not beneficial, thus making the firm less willing to lobby than it would if the future tax was certain. The conditions in Proposition 1 guarantee that other features of the curvature of $J(\cdot)$ are dominated by the effects of the convexity of $J(\cdot)$.

\footnotetext{
${ }^{8}$ To understand the convexity, note that if after time $T$, the firm sticks to a fixed abatement investment path for all values of $\tau,(3)$ shows that the value function $J(\cdot)$ would be decreasing and linear in $\tau$. Of course, as $\tau$ varies, the firm will adjust its investment path accordingly to reduce the decrease in $J(\cdot)$, making $J(\cdot)$ convex in $\tau$.
} 
Since $d E J / d B_{T}>0$ and $d J\left(K_{T}, \hat{\tau}\right) / d B_{T}>0,(10)$ indicates that the marginal benefit of the lobby capital under uncertainty is smaller than that under certainty. Thus, compared with the certainty case, Proposition 1 shows that under plausible conditions, uncertainty reduces the incentive of the firm to lobby. Farzin and Kort (2000) showed that uncertainty also reduces the firm's incentive to invest in abatement capital. Thus, although lobbying crowds out abatement investment in both the certainty and uncertainty cases, the crowding-out effect of lobby capital is smaller when the future tax is uncertain than when it is certain. Or, stated differently, the presence of lobbying can mitigate the negative effects of uncertainty on abatement investment. This is an important result since the uncertainty of environmental regulations is a fact of life, as is the lobbying activity of firms to undermine those regulations. The result suggests that if the regulator's objective is to encourage pollution abatement investment through levying a pollution tax, then in the presence of active lobbying by firms, it may be wise not to commit to a specific future tax rate.

\section{Lobby Against the Timing of a Higher Tax}

Suppose the magnitude of the tax increase has been decided, but the firm can lobby to postpone the implementation of the new tax rate. This scenario may arise if the tax increase is mandated by a legislation, but the enforcing agency (e.g. the EPA) is left to determine the actual time table of implementation.

Let $\tau_{h}>\tau_{l}$ be the new tax rate that has been fixed, and $T$ be its effective date that the firm may influence. To build up intuition, we consider first a deterministic model. 


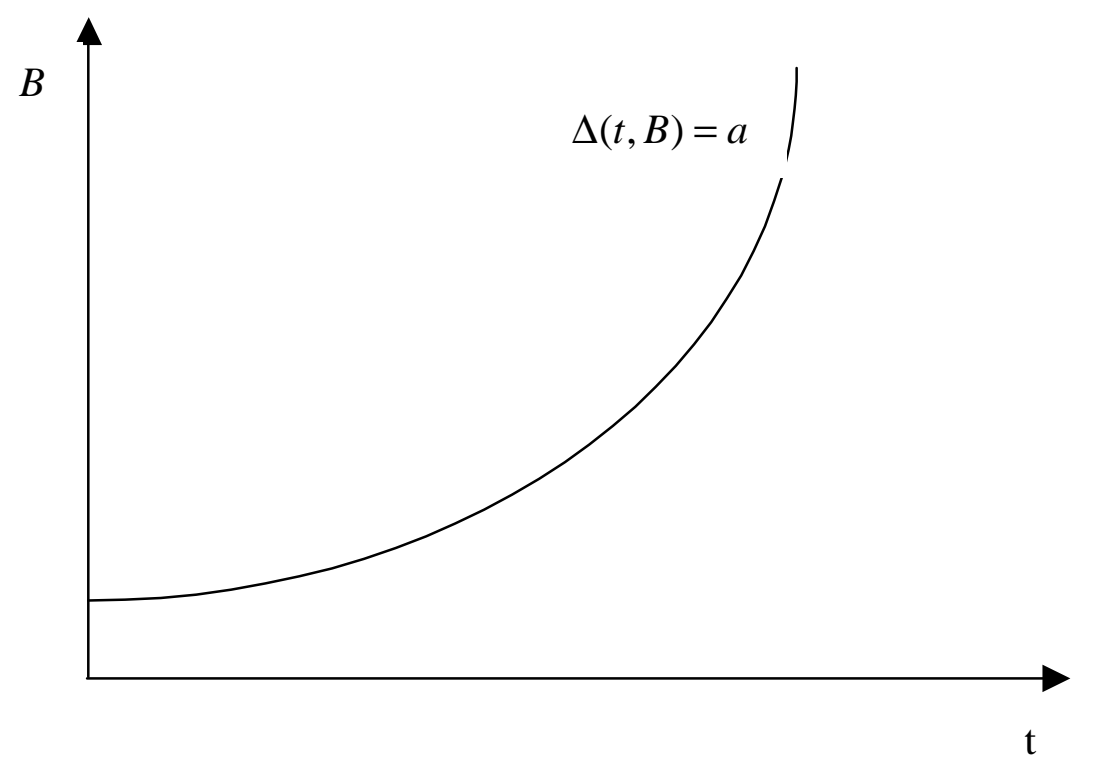

Figure 1: Isoquant of the Lobby Technology

\subsection{The Deterministic Scenario}

We first specify the lobby technology, or how effective the lobby capital stock $B$ is in delaying the new rate. Define $\Delta(t, B)$ as the additional length of delay of the new tax given that the policy has been delayed up to time $t$. We assume that $\Delta_{t}<0$, $\Delta_{t t}<0, \Delta_{B}>0, \Delta_{B B}<0$, and $\Delta_{t B}<0$. That is, given any lobby capital, as the new tax has been delayed for a longer time (or as $t$ increases), it becomes more difficult at an increasing rate to further delay it. At any time, higher lobby capital causes more delay of the new tax, but at a decreasing rate. Further, as time goes by, the lobby capital becomes less effective. Figure 1 graphs the isoquant in $t$ and $B$ : $\Delta(t, B)=a$, a fixed number. We can show that along the isoquant, $d B / d t>0$ and $d^{2} B / d t^{2}>0$. Thus as $t$ rises, it requires increasingly more and more lobby capital to delay the new tax by $a$ periods.

Suppose the firm decides to delay the new tax until time $T$. Intuitively, given 
the decreasing returns of the lobby capital, before $T$, the firm lobbies just enough to keep the tax not implemented. That is, it chooses $B(t)$ so that $\Delta(t, B(t))=0$ (or $\epsilon)$. This intuition is confirmed in the following Proposition, the proof of which is in Appendix B.

Proposition 2 Regardless of the abatement investment path $\{I(t), K(t)\}$, the least cost way of delaying the new tax until time $T$ requires $B(t)$ such that $\Delta(t, B(t))=0$ for all $t \leq T$.

Solving $\Delta(t, B(t))=0$, we obtain the optimal lobby capital stock $B^{*}(t)$ and the required lobby investment $l^{*}(t)$. From the characteristics of $\Delta(t, B)$, we know $B^{*}(t)$ is increasing at an increasing rate over time: $\dot{B}^{*}>0, \ddot{B}^{*}>0$. Since $l=\dot{B}+\gamma B$, we know $i^{*}(t)>0$. The firm's behavior of continuous lobbying is similar to that of "habitual lobbyers" (Morck, et al.). Its lobby expenditure increases overtime, and its lobby capital increases at an increasing rate overtime (thus the lobby expenditure more than offsets the depreciation of the lobby capital).

The firm's overall optimization problem is one of choosing the level of abatement investment and the time to delay the new tax to:

$$
\begin{gathered}
\max _{I, T} \int_{0}^{T} e^{-r t}\left[\pi\left(\tau_{l}, K(t)\right)-C(I(t))-l^{*}(t)\right] d t \\
\quad+\int_{T}^{\infty} e^{-r t}\left[\pi\left(\tau_{h}, K(t)\right)-C(I(t))\right] d t
\end{gathered}
$$

subject to (1). We form two Hamiltonians $H^{1}=\pi\left(\tau_{l}, K\right)-C(I)-l^{*}(t)+\lambda_{1}(I-\delta K)$ for $t \leq T$, and $H^{2}=\pi\left(\tau_{h}, K\right)-C(I)+\lambda_{2}(I-\delta K)$ for $t>T$. In addition to the regular necessary conditions, we have the following conditions:

$$
H^{1}(T)=H^{2}(T), \quad \lambda_{1}(T)=\lambda_{2}(T) .
$$

We assume that the optimal $T$ is in $(0, \infty)$ to avoid corner solutions. 
From the first order conditions on $I(t)$, we know from $H^{1}$ that $C^{\prime}\left(I\left(T^{-}\right)\right)=\lambda_{1}(T)$ and from $H^{2}$ that $C^{\prime}\left(I\left(T^{+}\right)\right)=\lambda_{2}(T)$. (12) then implies that $I(t)$ is continuous at time $T$, and consequently $K\left(T^{-}\right)=K\left(T^{+}\right)$. Therefore, $H^{1}(T)=H^{2}(T)$ implies that

$$
l^{*}(T)=\pi\left(\tau_{l}, K(T)\right)-\pi\left(\tau_{h}, K(T)\right)
$$

This equation uniquely determines the optimal time of the new policy (or optimal length of delay). To see this, notice that the LHS of (13) measures the marginal cost of delaying the new tax rate, and is increasing over time. The RHS measures the increased profit due to, or the marginal benefit of, delaying the new tax. Its time path is described by

$$
\left[\pi_{K}\left(\tau_{l}, K_{t}\right)-\pi_{K}\left(\tau_{h}, K_{t}\right)\right] \dot{K}(t)
$$

Applying the envelope theorem to (4), we know $\pi_{K}(\tau, K)=-\tau \alpha^{\prime}(K)$. Further, through a phase-diagram analysis, we show in Appendix $\mathrm{C}$ that $K(t)$ is monotone in time, and that since $K_{0}$ is low, $\dot{K}(t)>0$ for all $t>0$. So, the RHS of (13) is decreasing in $T$. Consequently, the optimal time of the new $\operatorname{tax} T$ is unique. (13) indicates that the firm delays the new tax rate until the marginal lobby expenditure required to delay the policy equals the marginal benefit of delaying the policy.

The equations of motion for $\lambda_{1}$ and $\lambda_{2}$ are

$$
\begin{aligned}
& \dot{\lambda}_{1}=(r+\delta) \lambda_{1}+\tau_{l} \alpha^{\prime}(K) \\
& \dot{\lambda}_{2}=(r+\delta) \lambda_{2}+\tau_{h} \alpha^{\prime}(K),
\end{aligned}
$$

which indicates that $\dot{\lambda}_{1}(T)>\dot{\lambda}_{2}(T)$ because $\lambda_{1}(T)=\lambda_{2}(T)$. Since $K_{0}$ is low and $K(t)$ is monotone, we know after time $T$, the system approaches the steady state from the left in Figure 5. Then for $t>T, I(t)$ decreases, and since $C^{\prime}(I)=\lambda_{i}$ for $i=1,2, \lambda_{2}(t)$ decreases.

Figure 2 depicts the paths of $\lambda_{1}(t)$ and $\lambda_{2}(t)$, which cross at time $T$. The path of $\lambda_{2}(t)$ is independent of the decision on $T$ : from the phase diagram in Figure 5, the 


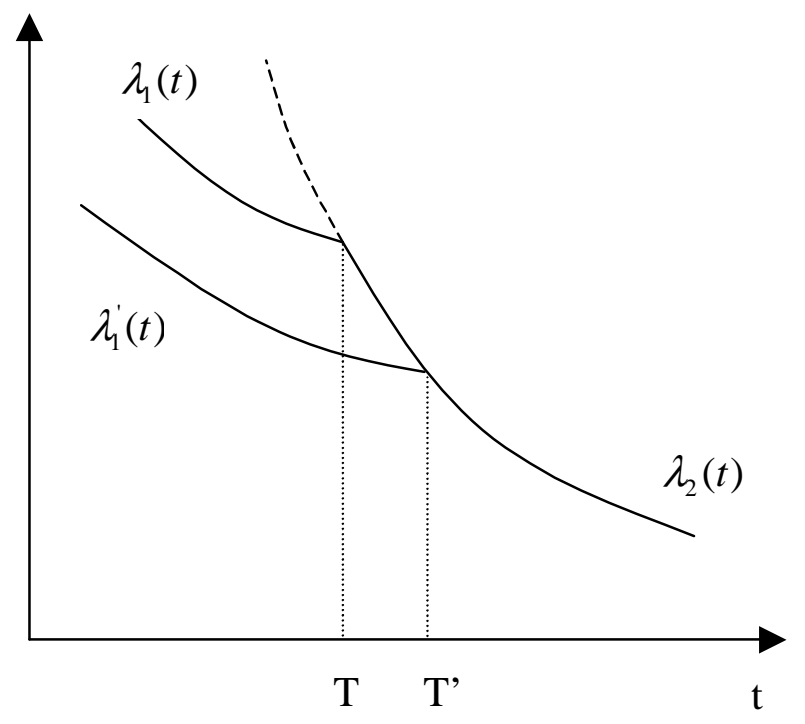

Figure 2: Time Paths of the Costate Variables

path of $\lambda_{2}(t)$ is determined entirely by the location of the steady state. Thus as the optimal switch time $T$ changes, only the $\lambda_{1}(t)$ path changes: since the costate variable measures the present value of all future contributions of more capital stock now, the timing of a future higher tax would affect $\lambda_{1}(t)$. Thus as $T$ is further delayed, say if the lobby technology becomes more efficient, or $l^{*}(t)$ decreases, the path of $\lambda_{1}(t)$ must shift down in Figure 2. Consequently, $I(t)$ must decrease for $t<T$. Further, at the time of the policy switch, $\lambda_{2}(T)$ is smaller the higher is $T$. Therefore, $I(T)$ is smaller, and from Figure 5, $I(t)$ must be smaller for $t>T$ as well. In particular, the optimal path changes from (V) to (VII). Thus $K(T)$ must be higher. From (13), the difference between the profit functions is smaller: as the abatement capital stock is higher, the savings from a lower tax rate is lower. (We can verify that $\pi_{\tau K}=-\alpha^{\prime}(K) q^{*}>0$.) Thus $l^{*}(T)$ is lower. In summary, we know

Proposition 3 As the lobby technology becomes more efficient, (i) the implementation time of the new tax rate will be delayed; (ii) the abatement investment $I(t)$ 
decreases both before and after the new tax is implemented; (iii) the abatement capital stock at the time of tax rate change is higher, after balancing the lower investment rate and the longer period of time before the new tax takes place; and (iv) the required lobby expenditure at the time of policy change is smaller, again after balancing the lower expenditure at each time period (due to higher lobby efficiency) and longer lobby time.

\subsection{The Stochastic Scenario}

Suppose now that lobbying can only delay the implementation with a positive probability. In particular, let $h(t, B)$ be the probability that the new tax rate is delayed given that it has not been implemented yet at time $t$. Similar to $\Delta(\cdot)$, we assume that $h_{t}<0, h_{t t}<0, h_{B}>0, h_{B B}<0$, and $h_{t B}<0$. Thus the isoquant of $h(t, B)=b$, a constant, is similar to that of $\Delta(t, B)=a$ in Figure 1.

We know from (3) that the firm's net payoff after the new tax rate is implemented at time $t$ is given by $J\left(K, \tau_{h}\right)$. Then at each moment before the implementation time, the firm's optimal decision is given by the following recursive equation:

$$
\begin{aligned}
U(t, K(t), B(t))= & \max _{I(t), l(t)}\left\{\left[\pi\left(\tau_{l}, K\right)-C(I(t))-l(t)\right] d t\right. \\
& +e^{-r d t}\left[[1-h(t, B(t))] d t J\left(K(t+d t), \tau_{h}\right)\right. \\
& +[1-(1-h(t, B(t))) d t] U(t+d t, K(t+d t), B(t+d t))]\} .
\end{aligned}
$$

On the RHS, the first line measures the firm's payoff in the "current" period, from $t$ to $t+d t$. The second and third lines measure the expected present value of the firm's payoff, which has two components. If the new rate is not delayed (with probability $(1-h) d t)$, the firm receives payoff $J(\cdot)$. If the rate is successfully delayed (with probability $1-(1-h) d t)$, the firm then has to redo the optimization problem for the "next" period, receiving payoff $U(\cdot)$.

Applying Taylor expansion to the RHS of (15), and ignoring higher order terms 
of $d t$, we get

$$
r U=\max _{I, l}\left\{\pi\left(\tau_{l}, K\right)-C(I)-l+d U / d t+(1-h)(J-U)\right\}
$$

which is the arbitrage condition: the return of the payoff $U(\cdot), r U$, must equal the current payoff plus the change in the total payoff $d U / d t$, adjusted by the possibility of a tax change. Substituting in the two state equations (1) and (2) gives

$$
r U+(1-h)(U-J)-U_{t}=\max _{I, l}\left\{\pi\left(\tau_{l}, K\right)-C(I)-l+U_{K}(I-\delta K)+U_{B}(l-\gamma B)\right\} .
$$

The first order conditions for $I$ and $l$ are

$$
\begin{gathered}
-C^{\prime}(I)+U_{K}(t, K, B)=0 \\
U_{B}(t, K, B) \leq 1, \quad l= \begin{cases}0 & \text { if } U_{B}<1 \\
\text { free } & \text { if } U_{B}=1\end{cases}
\end{gathered}
$$

The optimal investment and lobby paths can be found from these equations if $U(\cdot)$ is known.

Taking the derivative of (17) with respect to $B$ and adjusting lead to

$$
\dot{U}_{B}=[r+\gamma+(1-h)] U_{B}-h_{B}(U-J),
$$

where $\dot{U}_{B}=\frac{d U_{B}}{d t}=\frac{d}{d t}\left(\frac{\partial U}{\partial B}\right)$, which should be distinguished from $\frac{\partial}{\partial B}\left(\frac{d U}{d t}\right)$. This equation indicates that the marginal benefit of lobby investment, $U_{B}$, is given by

$$
\begin{aligned}
U_{B}(t, K(t), B(t))= & \int_{t}^{\infty} e^{-[r+\gamma+(1-h)](s-t)} \\
& h_{B}(s, B(s))\left[U(s, K(s), B(s))-J\left(K(s), \tau_{h}\right)\right] d s
\end{aligned}
$$

which measures the future expected benefits of possibly having the lower tax rate. To see this, note that $h_{B}(U-J)$ in period $s$ measures the expected benefit of increasing the lobby stock by one unit if the period $s$ can be reached, or if the new tax is delayed until at least period $s$. But period $s$ may not be reached at all, since there is always 
a probability of $(1-h)$ at each moment that the new tax rate is enacted. That is, $1-h(v, B(v)), v \in[t, s]$, is the hazard rate of a "sudden death" of the low tax rate $\tau_{l}$. Thus the period $s$ benefit $h_{B}(s, B(s))(U-J)$ must be discounted by the hazard rate, leading to $(1-h)$ in the discount factor. Further, since the lobby capital depreciates at rate $\gamma$, the future benefits must in addition be discounted at rate $\gamma$.

Suppose $l(t)>0$ on a time interval. Then $U_{B}=1$ and $\dot{U}_{B}=0$. Then the above equation implies

$$
r+\gamma+(1-h(t, B))=h_{B}(t, B)\left(U(t, K, B)-J\left(K, \tau_{h}\right)\right)
$$

The RHS measures the "marginal payoff" of increasing the lobby stock: the increase in the probability of delaying the new policy multiplied by the payoff of a successful delay.

\subsection{The Effects of Uncertainty}

Since $h(t, B)$ is the probability of delaying the new tax by one period, and $1-h(t, B)$ is the probability of no delay, the expected length of delay is $h(t, B)$. Thus, there is a direct correspondence between $h(t, B)$ and the length of delay $\Delta(t, B)$ in the deterministic model. If the firm has the same lobby technology in the deterministic and stochastic models, we would expect that $h(t, B)=\Delta(t, B)$, at least for $\Delta \leq 1$.

Therefore, to compare the lobby behaviors under certainty and uncertainty, we only need to compare the equilibrium levels of $h(t, B)$ and $\Delta(t, B)$. From (18), we know that as long as there is positive lobby expenditure, $h(t, B)$ cannot be zero for any positive length of time. (Otherwise, if $h\left(t, B_{t}\right)=0$ for an interval of time, $h_{B}=0$ on that interval, violating (18).) However, we know from Proposition 2 that lobby under certainty only guarantees that $\Delta\left(t, B_{t}\right)=0$. Therefore, there is more lobbying under uncertainty than under certainty. This is in direct contrast to the case of lobbying against the magnitude of the tax, where under plausible 
conditions the firm lobbies less under uncertainty. The economic intuition behind this contrasting result is that in the present case the benefit from delaying $\tau_{h}$ by $T$ is increasing and concave in $T^{9}$. The concavity of the payoff in $T$ implies that the firm prefers certainty over uncertainty in the implementation date. However, under uncertainty, in (15), the level of uncertainty, or the variance, of the implementation date is $(1-h) d t(1-(1-h) d t)$. Since $d t$ is small, this variance decreases as $h$ increases, or as the firm lobbies more. That is, lobbying under uncertainty has two benefits: it delays the expected implementation date and reduces its uncertainty. Thus, the firm lobbies more when the implementation date of the future tax is uncertain than when it is certain.

\section{Conclusion}

Lobbying against (or for) regulation legislation by private interest groups is a fact of economic life, at least in democratic societies. Within a dynamic framework, we have analyzed the lobby behavior of polluting firms and its effect on their investment in pollution abatement capital. In our model, firms spend resources on lobbying with the objective of either mitigating the magnitude of a future pollution tax increase or delaying its date of enactment. We have shown that the optimal lobby behavior and its impact on abatement investment depends on the lobby objective pursued by the firms. Thus, when the date of the pollution tax increase is fixed but firms can lobby to reduce its size, they behave like "occasional lobbyers" by spending a total (optimal) amount only at the moment when the tax increase is due. Further, by rendering abatement capital less valuable, the discrete lobby expenditure reduces the rate of expenditure on abatement capital at all times- a "crowding out" effect- thus

\footnotetext{
${ }^{9}$ The former follows from (13) and the latter from (14) and $\pi_{K}(\tau, K)=-\tau \alpha^{\prime}(K)$.
} 
resulting in a smaller abatement capital stock and hence a higher pollution intensity of output than would be the case without lobbying.

We have next analyzed the case where the size of the tax increase is already legislated but firms can lobby to delay its enactment date according to a deterministic lobby technology. For this case, we have shown that there is a unique optimal delaying period and, contrary to the previous case, the firms' optimal lobby behavior is similar to that of "habitual lobbyers:" they lobby continuously and at increasing rates. Moreover, the more efficient the lobby technology is the longer the optimal delaying period and the more intense will be the crowding-out effect of the lobby expenditure on abatement investment, although, at the time of the policy change the abatement capital stock will be larger and the required lobby expenditure will be smaller. The "habitual lobbyers" behavior is shown to be optimal also for the case where the lobby expenditure influences the probability of delaying the enactment date of the new policy.

Depending on the type of lobbying, uncertainty can play opposite roles. For occasional lobbyers who lobby against the magnitude of the tax, uncertainty reduces incentive to lobby. But for habitual lobbyists who lobby against the timing, uncertainty raises lobby expenditure. Thus, lobby can either mitigate or aggravate the negative impacts of uncertainty on abatement investment.

This research can be extended in several important directions. One can consider the more general situation where the firm's lobby expenditures may both mitigate the magnitude of the pollution tax increase and delay the date at which the policy is enacted. It is then possible to derive a number of insights about the characteristics of the optimal paths of investment in lobbying and abatement capital. Optimal lobbying would involve both continuous lobby investment before the policy change and a jump in investment level immediately prior to the change. Further, where the crowding- 
out effect of lobby expenditure on abatement investment is deemed to reduce social welfare, one can consider the options available to the government to regulate the lobby activity. For example, the government agency may care about lobby contributions and therefore not wish to eliminate lobbying, but can commit to either a time of policy change or a magnitude of policy change to reduce the lobby effectiveness. Which type of commitment is more efficient depends in part on the magnitude by which the continuous and the discrete lobby expenditures crowd out the abatement investment. We have not been specific about how the lobby expenditures are actually spent. In situations where they take the form of contributions to electoral political campaigns or become a source of public fund, as often considered in the literature, it would be interesting to examine how their effects on abatement investment would differ from those analyzed here. Finally, of particular value will be future empirical studies of the lobby effects analyzed in this paper. 


\section{A The Optimal Control Problem after Time $T$}

Forming the Hamiltonian of the optimization problem in (3), we can show that the first order condition of $I(t)$ is $\lambda(t)=C^{\prime}(I(t))$, which implies $\dot{\lambda}=C^{\prime \prime} \dot{I}$, where $\lambda(t)$ is the costate variable for $K$. The equation of motion for $\lambda$ is $\dot{\lambda}=r \lambda+\tau \alpha^{\prime}(K) q+\lambda \delta$. Combining the two equations, we know

$$
\dot{I}=\frac{1}{C^{\prime \prime}}\left[(r+\delta) C^{\prime}(I)+\tau \alpha^{\prime}(K) q\right]
$$

This equation and (1) form two differential equations in $I(t)$ and $K(t)$. Their phase

diagram in the $K-I$ space is presented in Figure 3. In particular, the $\dot{I}=0$ curve is downward slopping and the $\dot{K}=0$ curve is upward slopping. There is a unique steady state and a unique saddle path approaching the steady state from both sides. If $K_{T}<K^{*}$ (the steady state capital stock level), $K(t)$ increases and $I(t)$ decreases along the optimal path. If $K_{T}>K^{*}, K(t)$ decreases and $I(t)$ increases along the optimal path.

Consider now an increase in the "starting" capital level $K_{T}$, say from $K_{T}^{0}$ to $K_{T}^{1}$. Let $K_{t}^{0}$ and $K_{t}^{1}$ be the capital stock along the saddle path at time $t>T$, starting at $K_{T}^{0}$ and $K_{T}^{1}$ respectively. Let $t^{0}>T$ be the moment at which $K_{t}^{0}$ reaches $K_{T}^{1}$, i.e., $K_{T}^{1}=K_{t^{0}>T}^{0}$. Then $K_{t}^{1}=K_{t+t^{0}-T}^{0}$. Since $K_{t}$ is increasing in time, we know $K_{t}^{1}>K_{t}^{0}$ : the abatement stock after $T$ is increasing in the starting stock level $K_{T}$. Similarly, we can show that the investment rate $I_{t}$ is decreasing in $K_{T}$.

Consider an increase in $\tau$. From (19), we know the $\dot{I}=0$ isoquant shifts out in Figure 3, resulting in higher steady state levels of $K$ and $I$, as well as a higher saddle path. Then, given the same starting $K_{T}$, a higher $\tau$ leads to higher $I_{t}$ and consequently higher $K_{t}, t>T$. 


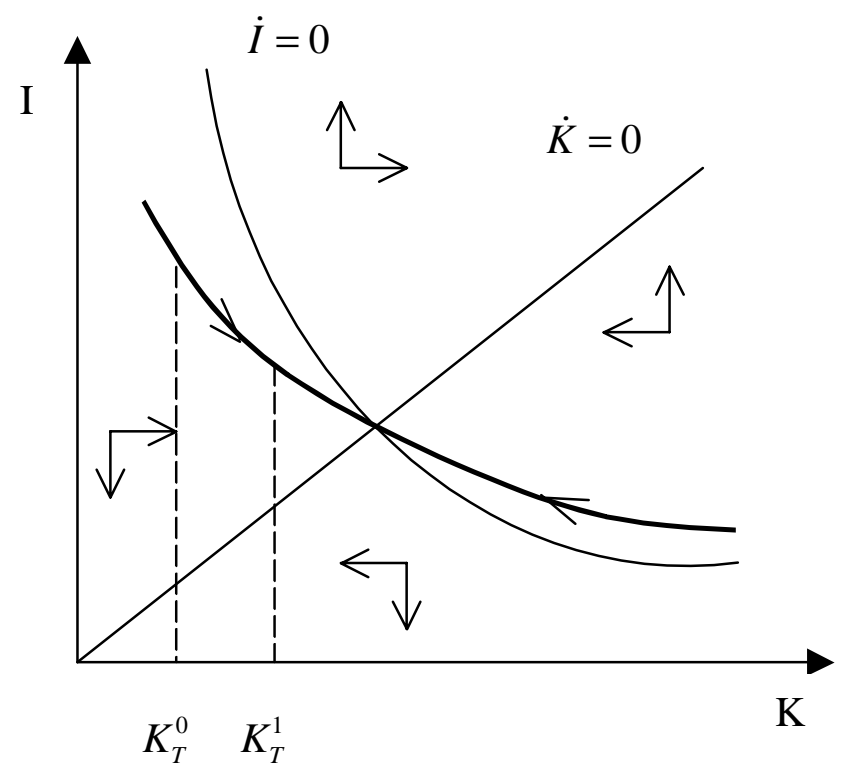

Figure 3: Phase Diagram

\section{B Proofs of Propositions}

Proof of Proposition 1. We first establish that $J\left(K_{T}, \tau\right)$ is convex in $\tau$. From (5), we know

$$
\begin{aligned}
\frac{\partial^{2} J\left(K_{T}, \tau\right)}{\partial \tau^{2}} & =-\int_{T}^{\infty} e^{-r(t-T)} \frac{d\left[\alpha\left(K_{t}^{*}\right) q_{t}^{*}\right]}{d \tau} d t \\
& =-\int_{T}^{\infty} e^{-r(t-T)} \frac{d\left[\alpha\left(K_{t}^{*}\right) q_{t}^{*}\right]}{d K_{t}^{*}} \frac{d K_{t}^{*}}{d \tau} d t
\end{aligned}
$$

Appendix A shows that $\frac{d K_{t}^{*}}{d \tau}>0$, and we know $\frac{d\left[\alpha\left(K_{t}^{*}\right) q_{t}^{*}\right]}{d K_{t}^{*}}<0$ from Assumption 1 . Thus, $J\left(K_{T}, \cdot\right)$ is convex.

The convexity implies that

$$
E J\left(K_{T}, \tau\right)<\frac{J\left(K_{T}, \tau_{h}\right)+J\left(K_{T}, \tau_{l}\right)}{2}
$$

To see this, note that (21) is equivalent to

$$
\int_{\tau_{l}}^{\tau_{h}}\left[J\left(K_{T}, \tau_{l}\right)-J\left(K_{T}, \tau\right)\right] d \tau>\int_{\tau_{l}}^{\tau_{h}}\left[J\left(K_{T}, \tau\right)-J\left(K_{T}, \tau_{h}\right)\right] d \tau
$$




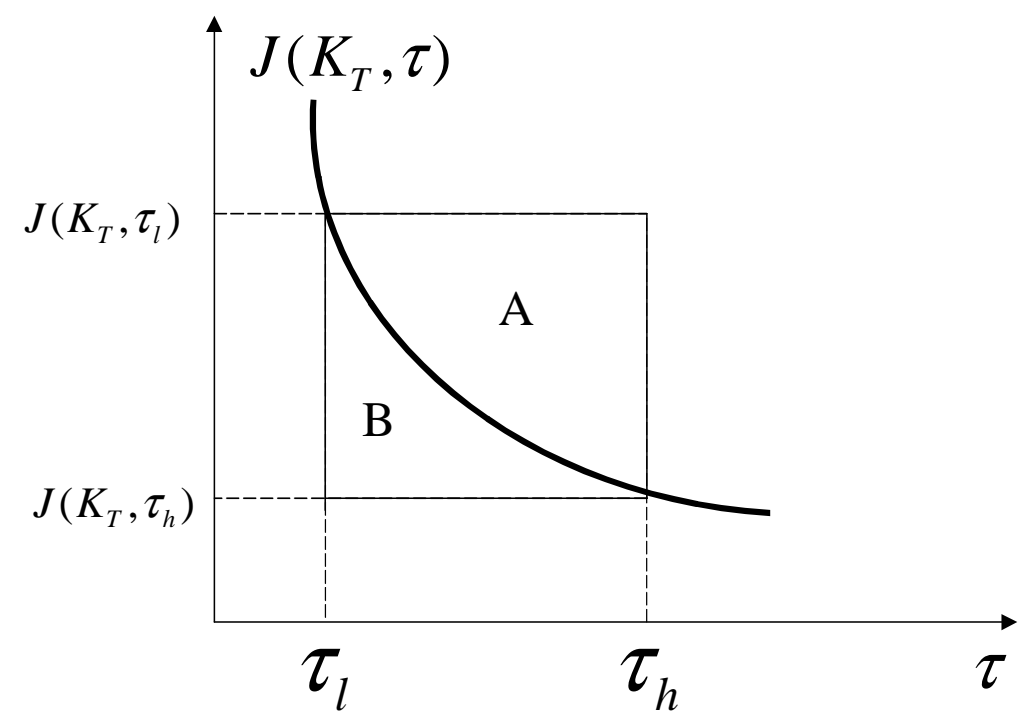

Figure 4: Convexity of $J\left(K_{T}, \tau\right)$

The left hand side measures area $\mathrm{A}$ in Figure 4, while the right hand side measures area B. Since $J\left(K_{T}, \cdot\right)$ is convex, we know area A is larger than B.

Now we prove Proposition 1. From (7), we know

$$
\frac{\partial E_{\tau \mid \tau_{h}\left(B_{T}\right)} J\left(K_{T}, \tau\right)}{\partial B_{T}}=\left[-\frac{E J\left(K_{T}, \tau\right)}{\tau_{h}-\tau_{l}}+\frac{J\left(K_{T}, \tau_{h}\right)}{\tau_{h}-\tau_{l}}\right] \frac{d \tau_{h}}{d B_{T}} .
$$

Using this equation and $d \hat{\tau} / d B_{T}=(1 / 2)\left(d \tau_{h} / d B_{T}\right)$, we know

$$
\begin{aligned}
& \frac{\partial E_{\tau \mid \tau_{h}\left(B_{T}\right)} J\left(K_{T}, \tau\right)}{\partial B_{T}}-\frac{\partial J\left(K_{T}, \hat{\tau}\left(B_{T}\right)\right)}{\partial B_{T}} \\
& =\left[-\frac{E J\left(K_{T}, \tau\right)}{\tau_{h}-\tau_{l}}+\frac{J\left(K_{T}, \tau_{h}\right)}{\tau_{h}-\tau_{l}}-\frac{1}{2} \frac{\partial J\left(K_{T}, \hat{\tau}\right)}{\partial \tau}\right] \frac{d \tau_{h}}{d B_{T}}, \\
& <\frac{1}{2}\left[\frac{J\left(K_{T}, \tau_{h}\right)-J\left(K_{T}, \tau_{l}\right)}{\tau_{h}-\tau_{l}}-\frac{\partial J\left(K_{T}, \hat{\tau}\right)}{\partial \tau}\right] \frac{d \tau_{h}}{d B_{T}}
\end{aligned}
$$

where the inequality follows from (21) and the fact that $\frac{d \tau_{h}}{d B_{T}}<0$. Applying third order Taylor expansion of $J\left(K_{T}, \tau_{h}\right)$ around $\tau_{l}$, we know the term in the square bracket of the last line in (22) approximately equals

$$
J_{\tau}\left(K_{T}, \tau_{l}\right)-J_{\tau}\left(K_{T}, \hat{\tau}\right)+\frac{1}{2} J_{\tau \tau}\left(K_{T}, \tau_{l}\right)\left(\tau_{h}-\tau_{l}\right)+\frac{1}{6} J_{\tau \tau \tau}\left(K_{T}, \tau_{l}\right)\left(\tau_{h}-\tau_{l}\right)^{2} .
$$


Applying second order Taylor expansion of $J_{\tau}\left(K_{T}, \hat{\tau}\right)$ around $\tau_{l}$, we know

$$
J_{\tau}\left(K_{T}, \tau_{l}\right)-J_{\tau}\left(K_{T}, \hat{\tau}\right)=-J_{\tau \tau}\left(K_{T}, \tau_{l}\right)\left(\hat{\tau}-\tau_{l}\right)-\frac{1}{2} J_{\tau \tau \tau}\left(K_{T}, \tau_{l}\right)\left(\hat{\tau}-\tau_{l}\right)^{2}
$$

Substituting (24) into (23), and noting that $\left(\tau_{h}-\tau_{l}\right) / 2-\left(\hat{\tau}-\tau_{l}\right)=0$, we know $(23)$ equals

$$
J_{\tau \tau \tau}\left(K_{T}, \tau_{l}\right)\left[+\frac{1}{6}\left(\tau_{h}-\tau_{l}\right)^{2}-\frac{1}{2}\left(\hat{\tau}-\tau_{l}\right)^{2}\right] .
$$

We can easily verify that the term in the square bracket is positive. Thus if conditions (i) or (ii) in the Proposition are satisfied, the errors in Taylor expansion are small relative to the inequality in (22). The Proposition then follows.

Proof of Proposition 2. Given any abatement investment path $\{I(t), K(t)\}$, the firm's optimization problem of delaying the new tax to period $T$ is

$$
\begin{aligned}
& \max _{l}-\int_{0}^{T} e^{-r t} l(t) d t \\
& \text { s.t. } \quad \Delta(t, B(t)) \geq 0, \text { and }(2), \text { for } t \leq T \text {. }
\end{aligned}
$$

The current value Hamiltonian is $H(B(t), l(t), \rho(t))=-l(t)+\rho(t)(l(t)-\gamma B(t))$, where $\rho(t)$ is the current value costate variable associated with $B(t)$. The Lagrangian is $L=H+\mu(t) \Delta(t, B)$, where $\mu(t)$ is associated with the inequality constraint.

The necessary conditions are

$$
\begin{gathered}
\rho(t) \leq 1, \quad l(t)=0 \quad \text { if } \rho(t)<1, \quad \text { and } \quad l(t) \text { is free if } \rho(t)=1, \\
\dot{\rho}=r \rho+\gamma \rho-\mu \Delta_{B}, \\
\mu(t) \geq 0, \quad \Delta(\cdot) \geq 0, \quad \mu \Delta(\cdot)=0,
\end{gathered}
$$

and the constraints in the optimization problem. Since $B_{0}=0, l(t)>0$ for small $t$, say for $t \in\left[0, t_{1}\right]$ for some $t_{1}<T$. Then $\rho(t)=1$ or $\dot{\rho}(t)=0$ for all $t \leq t_{1}$. Consequently $\mu(t)=(r+\gamma) \rho(t) / \Delta_{B}>0$, which implies $\Delta(t, B(t))=0$. Further, immediately after $t_{1}, B(t)$ must be higher than $B\left(t_{1}\right)$ to make sure $\Delta(t, B(t)) \geq 0$ (cf. Figure 1). Thus $l(t)>\gamma B(t)>0$ for $t>t_{1}$. Again this condition implies that 


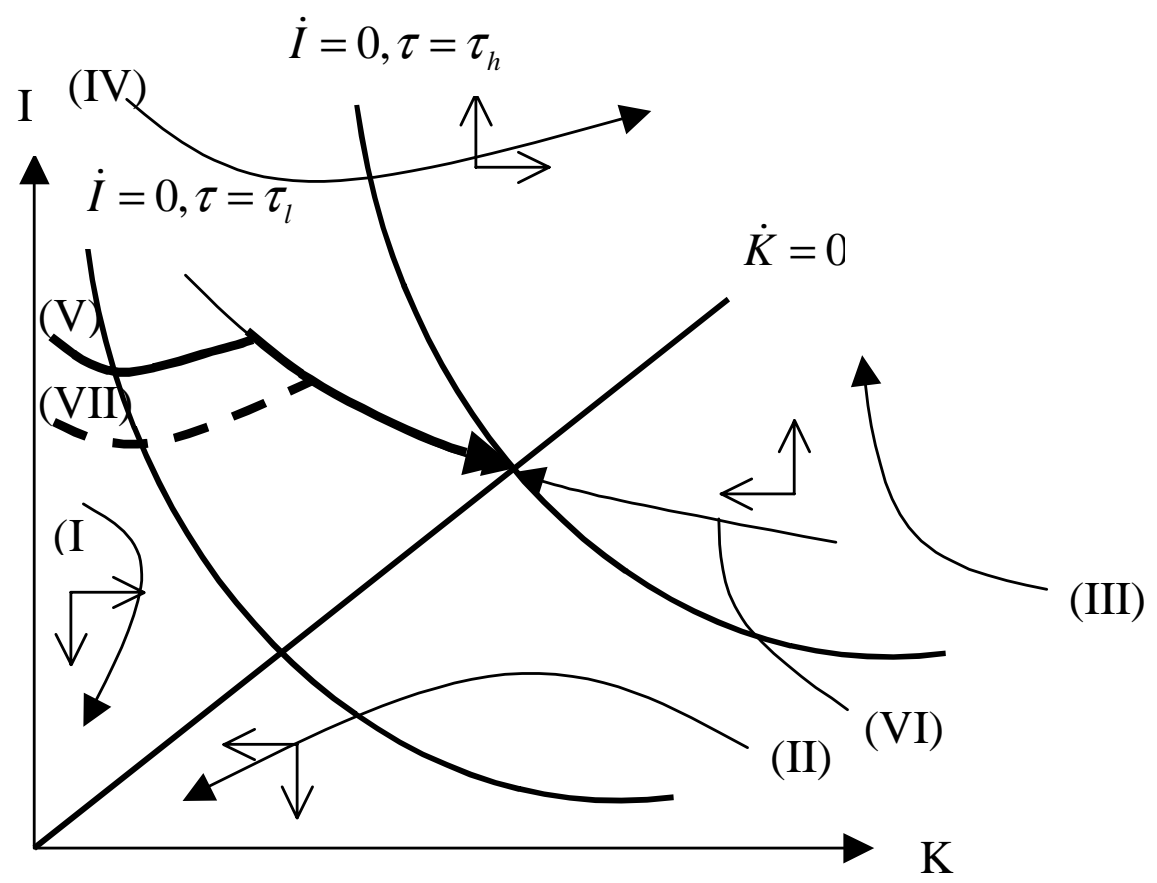

Figure 5: Phase Diagram for Control Problem (11)

$\rho(t)=1$, or $\mu(t)>0$, or $\Delta(t, B(t))=0$ for $t>t_{1}$. Continuing this argument, we know $\Delta(t, B(t))=0$ for all $t \leq T$.

\section{Optimal Paths of the Control Problem (11)}

The equation of motion $\dot{I}(t)$ is the same as (19), with $\tau$ replaced by $\tau_{l}$ and $\tau_{h}$ for $t \leq T$ and $t>T$ respectively. Thus the phase diagram of the control problem, shown in Figure 5, is similar to Figure 3, except that there are two $\dot{I}=0$ isoclines, one for $\tau=\tau_{l}$ and one for $\tau=\tau_{h}$. Only paths (V) and (VI) can reach the steady state $S$. For example, on path (I), the system moves towards the origin under both $\tau=\tau_{l}$ and $\tau=\tau_{h}$. Since $K_{0}$ is small, we know the optimal path is $(\mathrm{V})$. 


\section{References}

[1] Bartsch, E., Rauscher, M., and I. Thomas (1993), "Environmental Legislation and The Impact of Lobbying Activities", Keil Working Paper No. 562, Kiel Institute of World Economics

[2] Becker, G.S. (1983), "A Theory of Competition among Pressure Groups for Political Influence", Quarterly Journal of Economics, Vol. 158, No. 3, 371-399, August.

[3] Becker, G.S. (1985), "Public Policies, Pressure Groups and Deadweight Costs", Journal of Public Economics, Vol. 28, 329-347.

[4] Bernheim, B.D. and M.D. Winston (1986a), "Common Agency", Econometrica, 54, 923-942.

[5] Bernheim, B.D. and M.D. Winston (1986b), "Menu Auctions, Resource Allocation, and Economic Influence", Quarterly Journal of Economics, 101, 1-31.

[6] Damania, R. (2001), "When the Weak Win: The Role of Investment in Environmental Lobbying", Journal of Environmental Economics and Management, 42, $1-22$.

[7] Dixit, A.K., G.M. Grossman and E. Helpman (1997), "Common Agency and Coordination: General Theory and Application to Government Policy Making", Journal of Political Economy, Vol. 105, No. 4: 752-769

[8] Doyle, J.,(2000), Taken For a Ride: Detroit's Big Three and The Politics of Pollution, Four Walls Eight Windows, London. 
[9] Farzin, Y. H. and P.M. Kort (2000), "Pollution Abatement Investment When Environmental Regulation is Uncertain", Journal of Public Economic Theory, Vol.2, No.2, April.

[10] Fredriksson, P.G. (1997), "The Political Economy of Pollution Taxes in a Small Open Economy", Journal of Environmental Economics and Management, Vol.33, No.1,44-58.

[11] Fredriksson, P.G. and N. Gaston (2000), "Environmental Governance in Federal Systems: The Effects of Capital Competition and Lobby groups", Economic Inquiry, Vol. 38, No. 3, July, 501-514.

[12] Grossman, G.M. and E. Helpman (1994), "Protection for Sale", American Economic Review, Vol.48, No. 4, 833-850.

[13] Gulati, S. (1999), "Endogenous Pollution Taxes and Redistribution in a Small Open Economy", Paper presented at the Annual Conference of American Agricultural Economics Association (AAEA), Nashville, August 9-11, 1999.

[14] Michaelis, P. (1994), "Regulate Us, Please! On Strategic Lobbying in CournotNash Oligopoly", Journal of Institutional and Theoretical Economics, Vol. 150, No.4, 693-709.

[15] Morck, R. , J. Spanski, and B.Yeung (2001), "Habitual and Occasional Lobbyers in the US Steel Industry: An EM Algorithm Pooling Approach", Economic Inquiry, Vol.39, No.3, July, 365-379.

[16] Olson, M. (1965), The Logic of Collective Action, Cambridge MA: Harvard University Press.

[17] Peltzman, S. (1976), "Toward a More General Theory of Regulation", Journal of Law and Economics, 19(2):211-240. 
[18] Persson, T. (1998), "Economic Policy and Special Interest Politics", The Economic Journal, Vol. 108, 310-327, March.

[19] Schleich, J. and D. Orden (2000), "Environmental Quality and Industry Protection with Noncooperative Versus Cooperative Domestic and Trade Policies", Review of International Economics, Vol.8, No.4, 681-97, November.

[20] Stigler, G.L. (1971), "The Theory of Economic Regulation", Bell Journal of Economics and Management, 2(1):3-21

[21] Tullock, G. (1980), "Efficient Rent-Seeking", in Buchanan J.M., R.D. Tollison and G. Tullock (eds.), Toward a Theory of the Rent-Seeking Society, 97-112.

[22] Tullock, G. (1989), The Economics of Special Privilege and Rent Seeking, Boston, MA: Kluwer Academic Publishers. 